\title{
Urinary excretion of glycosaminoglycans in the various forms of gargoylism
}

\author{
G. MANLEY AND U. WILLIAMS
}

From the Nuffield Department of Clinical Biochemistry, the Radcliffe Infirmary, Oxford

SYNOPSIS The urinary excretion of glycosaminoglycans in 28 cases of gargoylism, embracing the Hurler, Hunter, Sanfilippo, Morquio, and Scheie syndromes (McKusick, 1966), has been examined using the cetylpyridinium chloride (CPC) turbidity test, the uronic acid/creatinine ratio, and the electrophoretic pattern of urine concentrates, as routine procedures. Ion-exchange column chromatographic techniques were also employed for the fractionation of glycosaminoglycans and aminosugars. Molecular weights were investigated by gel filtration and ultracentrifugation.

The CPC turbidity test was positive in every case. The uronic acid/creatinine ratio provided a sensitive index of increased glycosaminoglycan excretion. Cases of the Hurler syndrome showed the highest, and cases of the Morquio and Scheie syndromes the lowest, ratios. A correlation was observed between the uronic acid/creatinine ratio and the clinical severity of the disease. Cellulose acetate electrophoresis differentiated clearly between the two major forms of gargoylism, the Hurler and Sanfilippo syndromes, but differentiation between the Hurler, Hunter, and Scheie syndromes was more difficult on electrophoretic data alone. Results obtained with cases diagnosed as the Morquio syndrome were disappointing. The existence of formes frustes of the Sanfilippo syndrome among the mentally subnormal is predicted. Errors caused by bacterial contamination of urine samples are emphasized. The atypical behaviour of urinary glycosaminoglycans in analytical procedures is discussed. Molecular weight studies suggested heterogeneity. The nature of the basic defect in gargoylism is discussed.

The condition 'gargoylism' has been known for about 60 years, the first detailed description being given by Hunter in 1917. Early histological studies showed vacuolated cells in many tissues, and in the belief that these were caused by fat dissolving out during processing, the term lipochondrodystrophy came into use (Washington, 1966). Then glycogen was thought to be involved in the disorder (de Lange, Gerlings, de Kleyn, and Lettinga, 1944) and only 11 years ago it was realized that glycosaminoglycans were primarily involved in the disease (Dorfman and Lorincz, 1957). Since then, studies of the urinary glycosaminoglycans in gargoylism, together with careful clinical and genetic documentation, has led to the recognition of six distinct entities within the group, which McKusick (1966) has called the Hurler, Hunter, Sanfilippo, Morquio, Scheie, and Maroteaux-Lamy syndromes.

Though many of the techniques used in the isolation and characterization of glycosaminoglycans cannot easily be employed in hospital

Received for publication 22 May 1968. laboratories, several simple tests have emerged for the detection of increased urinary glycosaminoglycan excretion (Berry and Spinanger, 1960; Denny and Dutton, 1962; Segni, Romano, and Tortorolo, 1964; Manley and Hawksworth, 1966). It has also been shown that simple cellulose acetate electrophoresis of urinary concentrates will differentiate between at least two types of gargoylism (Manley and Hawksworth, 1966). This paper presents a laboratory investigation of urinary glycosaminoglycans in 28 cases of gargoylism, in the light of current clinical classification.

\section{MATERIAL AND METHODS}

MATERIAL Twenty-eight cases of gargoylism form the basis of this study. A proforma listing relevant clinical features was completed by the clinician in charge of each case, and this data enabled each case to be assigned to one of the six mucopolysaccharidoses of McKusick. Urine was collected over a period of 24 hours, and preserved with merthiolate. When immediate analysis was impossible, the samples were stored at $-20^{\circ} \mathrm{C}$. 
ROUTINE METHODS The CPC turbidity, CPC-precipitable uronic acid level, and uronic acid/creatinine ratio were determined as described previously (Manley, Severn, and Hawksworth, 1968).

CONCENTRATION OF URINE FOR ELECTROPHORESIS This was carried out as described by Manley and Hawksworth (1966), with some modifications. Centrifuged urine (50 ml) was concentrated. A vacuum was applied to the Woulff's bottle by gas-ballast pump, and a regulatory valve, fitted with a vacuum gauge, was interposed between the pump and the Woulff's bottle so that the suction applied could be set exactly at $-710 \mathrm{~mm} \mathrm{Hg}$. The water in the Woulff's bottle was mixed by magnetic stirring. Concentration was carried out for 24 hours. The application of a controlled vacuum for a fixed time was found to favour reproducibility, for in this way the inevitable loss of glycosaminoglycans through the dialysis sac was standardized. The residue remaining in the sac after 24 hours was transferred quantitatively to AutoAnalyzer pots, and dried over silica gel.

SEPARATION OF GLYCOSAMINOGLYCANS BY ELECTROPHORESIS The dried urine concentrates were dissolved in $0.5 \mathrm{ml}$ water, and samples equivalent to 5 to $20 \mu \mathrm{g}$ uronic acid were applied to cellulose acetate strips as described previously (Manley and Hawksworth, 1966). After electrophoresis in Michaelis's veronal acetate buffer, $p H \mathbf{9 \cdot 2}$, at $20 \mathrm{v} / \mathrm{cm}$ for 80 minutes in a constant temperature room at $20^{\circ} \mathrm{C}$, the strips were stained for 30 minutes in a solution of $1 \%$ alcian blue in $2 \%$ acetic acid. After staining, the strips were transferred to a slowly rotating frame in a running-water bath, to wash for 30 minutes. Quantitation of the alcian blue-positive fractions was carried out in a Joyce Chromoscan as described previously.

DIGESTION WITH TESTICULAR HYALURONIDASE This was carried out as described in the previous paper (Manley et al, 1968), the glycosaminoglycans remaining in the digests and saline controls being separated by electrophoresis.

SEPARATION OF GLYCOSAMINOGLYCANS BY COLUMN CHROMATOGRAPHY Urine concentrates and urinary glycosaminoglycans prepared by CPC precipitation, containing an equivalent of $600 \mu \mathrm{g}$ of uronic acid, were applied to a $1 \times 40 \mathrm{~cm}$ column of Dowex $1 \mathrm{Cl} \times 2-400$, and eluted with an increasing $\mathrm{NaCl}$ gradient as described in the previous paper. The $\mathrm{NaCl}$ molarity of the column effluent was recorded automatically from the change in conductivity between two platinum-black electrodes set at either side of the column outlet. A small capillary placed between the electrodes conveyed the effluent to an AutoAnalyzer which performed continuous flow uronic acid analysis of the column effluent, employing an AutoAnalyzer adaptation of Bitter and Muir's (1962) modification of the carbazole method. Thus the $\mathrm{NaCl}$ and uronic acid concentration of the column effluent were recorded automatically.

HEXOSAMINE ASSAY Aliquots of urine concentrates, equivalent to $40 \mu \mathrm{g}$ uronic acid, were transferred to Pyrex tubes, and dried in vacuo over silica gel. Hydro-:chloric acid $(0.5 \mathrm{ml})$, twice distilled and adjusted to $4 \mathrm{~N} \underset{\boldsymbol{F}}{\overrightarrow{7}}$ was added to each. The tubes were filled with nitrogen and sealed. Hydrolysis was carried out at $100^{\circ} \mathrm{C}$ for eight hours. $\mathrm{HCl}$ was removed in vacuo over $\mathrm{KOH}$ 음 Water $(1.0 \mathrm{ml})$ was added and the hexosamine con- $\frac{5}{-}$ centration determined by Boas' (1953) modification of the Elson-Morgan reaction. For the column separation of glucosamine and galactosamine, an aliquot of the urines concentrate equivalent to $800 \mu \mathrm{g}$ of uronic acid wase hydrolysed in the same way.

COLUMN CHROMATOGRAPHIC SEPARATION OF GLUCOSAMINE AND GALACTOSAMINE Hydrolysates of urinary concen $?$ trates equivalent to $800 \mu \mathrm{g}$ of uronic acid were applied to a $1 \times 40 \mathrm{~cm}$. column of Dowex $\mathrm{H}^{+} \times 8-400$ and eluted with $0.3 \mathrm{M} \mathrm{HCl}$ at $6 \mathrm{ml} / \mathrm{hr}$ as described byos Gardell (1953). Effluent fractions $(1.0 \mathrm{ml})$ were collected in AutoAnalyzer pots by an LKB Radi Rac fraction? collector. The hexosamine content of each fraction was determined by an AutoAnalyzer adaptation of then Elson-Morgan reaction, using 0.3 M trisodium phosphate instead of sodium carbonate for the acetylation-con- vo densation procedure.

GEL-FILTRATION COLUMN CHROMATOGRAPHY OF GLYCO-శ SAMINOGLYCANS Urinary glycosaminoglycans prepared by CPC precipitation, equivalent to $200 \mu \mathrm{g}$ uronic acid, were dissolved in $0.5 \mathrm{M} \mathrm{NaCl}(1.0 \mathrm{ml})$ and applied to a $1 \times 100 \mathrm{~cm}$ column of Sephadex G 50 (fine) in $0.5 \overline{0}$ $\mathrm{M} \mathrm{NaCl}$. The column was eluted with $0.5 \mathrm{M} \mathrm{NaCl}$ ato $6 \mathrm{ml} / \mathrm{hr}$, and the effluent collected in fractions of $1.0 \mathrm{ml}$ in AutoAnalyzer pots. The uronic acid content of each fraction was determined by the AutoAnalyzer? adaptation of the carbazole method of Bitter and Muir (1962). Standard vascular chondroitin-6-sulphate, Mw. 48,000, and tetrasaccharides produced by the action of testicular hyahuronidase on chondroitin-6-sulphatewere prepared as described by Mullinger, Lloyd, and: Manley (1969).

ULTRACENTRIFUGAL SEDIMENTATION OF GLYCOSAMINO-O GLYCANS Urinary glycosaminoglycans were prepared as their sodium salts by CPC and alcohol precipitation.을 They were dissolved in $0.15 \mathrm{M} \mathrm{NaCl}$ to give a uronic acid concentration of $2.0 \mathrm{mg} / \mathrm{ml}$. Sedimentation velocity음 runs were carried out at $59,780 \mathrm{rev} / \mathrm{min}$ using Schlieren optics in a Beckman model $\mathrm{E}$ analytical ultracentrifuge.

TERMINOLOGY Gargoylism is used as an umbrella term N to include all the mucopolysaccharidoses. The suggestions of Jeanloz (1960) are followed for the nomenclature of mucopolysaccharides.

\section{RESULTS}

The age, sex, and relevant clinical features of the cases studied are shown in Table $I$, together with the $\frac{?}{\mathbb{P}}$ major chemical findings. For the typing of each $\mathrm{a}$ case, clinical and chemical features were taken intor 
TABLE I

MAJOR CLINICAL AND BIOCHEMICAL FEATURES IN 28 CASES OF GARGOYLISM

\begin{tabular}{|c|c|c|c|c|c|c|c|c|c|c|c|c|}
\hline \multirow[t]{2}{*}{ Case } & \multirow[t]{2}{*}{ Sex } & \multirow[t]{2}{*}{$\begin{array}{l}\text { Age } \\
(y r)\end{array}$} & \multirow[t]{2}{*}{$\begin{array}{l}\text { Corneal } \\
\text { Opacities }\end{array}$} & \multirow[t]{2}{*}{$\begin{array}{l}\text { Mental } \\
\text { Retard- } \\
\text { ation }\end{array}$} & \multirow[t]{2}{*}{$\begin{array}{l}\text { Cardio- } \\
\text { vascular } \\
\text { Affliction }\end{array}$} & \multirow[t]{2}{*}{$\begin{array}{l}\text { Skeletal } \\
\text { Affliction }\end{array}$} & \multirow[t]{2}{*}{$\begin{array}{l}\text { CPC } \\
\text { Turbidity }\end{array}$} & \multirow[t]{2}{*}{$\begin{array}{l}\text { Uronic Acid } \\
(\mathrm{mg} / 100 \mathrm{ml} \text { urine })\end{array}$} & \multirow[t]{2}{*}{$\begin{array}{l}\text { Uronic } \\
\text { Acid/ } \\
\text { Creatinine } \\
\text { Ratio }\end{array}$} & \multicolumn{2}{|c|}{$\begin{array}{l}\text { Percentage Total } \\
\text { Sulphated Glyco- } \\
\text { saininoglycans }\end{array}$} & \multirow[t]{2}{*}{ Type } \\
\hline & & & & & & & & & & HS & $\mathrm{CS}$ & \\
\hline AFo & $\mathbf{M}$ & $5 \frac{1}{2}$ & ++ & ++ & ++ & ++ & 0.76 & $12 \cdot 5$ & 236 & $5 \cdot 2$ & $94 \cdot 8$ & Hurler \\
\hline $\mathbf{A F i}$ & $\mathbf{M}$ & $1 \frac{1}{2}$ & ++ & + & - & ++ & 0.72 & $17 \cdot 1$ & 323 & $5 \cdot 8$ & $94 \cdot 2$ & Hurler \\
\hline DB & $\mathbf{M}$ & 2 & +++ & ++ & + & ++ & 0.62 & $4 \cdot 3$ & 196 & $7 \cdot 3$ & $92 \cdot 7$ & Hurler \\
\hline GG & $\mathbf{M}$ & 5 & ++ & ++ & 0 & + & 0.75 & 10.6 & 133 & $8 \cdot 3$ & 91.7 & Hurler \\
\hline JMo & $\mathrm{F}$ & 3 & ++ & ++ & 0 & $+t$ & 0.90 & $15 \cdot 6$ & 248 & $4 \cdot 8$ & $95 \cdot 2$ & Hurler \\
\hline PA & $\mathbf{M}$ & $1 \frac{1}{2}$ & 0 & + & 0 & + & 0.80 & 6.6 & 213 & $8 \cdot 2$ & $91 \cdot 8$ & ?Hurler \\
\hline SB & $\mathbf{M}$ & 5 & $++t$ & + & - & ++ & 0.76 & $10 \cdot 1$ & 191 & 5.8 & $94 \cdot 2$ & Hurler \\
\hline SD & $\mathbf{M}$ & $10 \frac{1}{2}$ & + & $++t$ & + & ++ & 0.60 & 13.0 & 184 & $9 \cdot 7$ & $90 \cdot 3$ & Hurler \\
\hline GK & $\mathbf{M}$ & $7 \frac{1}{2}$ & 0 & + & 0 & + & 0.71 & $9 \cdot 0$ & 120 & $31 \cdot 5$ & $68 \cdot 5$ & Hunter \\
\hline $\mathrm{JMe}$ & $\mathbf{M}$ & $5 \frac{1}{2}$ & 0 & + & ++ & + & 0.88 & 6.8 & 136 & $10 \cdot 8$ & $89 \cdot 2$ & ?Hunter \\
\hline JN & $\mathbf{M}$ & $9 / 12$ & 0 & + & 0 & 0 & 0.54 & $4 \cdot 2$ & 167 & $23 \cdot 0$ & $77 \cdot 0$ & Hunter \\
\hline PN & $\mathbf{M}$ & 4 & 0 & $++t$ & 0 & 0 & 0.60 & $4 \cdot \overline{7}$ & 80 & 19.9 & $80 \cdot 1$ & Hunter \\
\hline $\mathbf{C M}$ & $\mathbf{M}$ & 8 & 0 & ++ & + & + & 0.85 & $5 \cdot 6$ & 45 & $47 \cdot 2$ & $52 \cdot 8$ & Sanfilippo \\
\hline DM & $\mathbf{M}$ & 12 & 0 & ++ & 0 & 0 & 0.83 & $7 \cdot 0$ & 64 & 50.4 & 49.6 & Sanfilippo \\
\hline LM & $\mathbf{F}$ & 11 & 0 & ++ & 0 & 0 & 0.87 & $11 \cdot 4$ & 51 & $45 \cdot 4$ & $56 \cdot 6$ & Sanfilippo \\
\hline JF & $\mathbf{F}$ & 10 & 0 & $+t+$ & 0 & 0 & 0.68 & 8.6 & 133 & 80.0 & 20.0 & Sanfilippo \\
\hline JJ & $\mathbf{F}$ & $12 \frac{1}{2}$ & 0 & +++ & 0 & 0 & 0.68 & $8 \cdot 8$ & 43 & $55 \cdot 5$ & $44 \cdot 5$ & Sanfilippo \\
\hline $\mathbf{M M}$ & $\mathbf{M}$ & 6 & 0 & ++ & 0 & + & 0.80 & $6 \cdot 6$ & 41 & $63 \cdot 7$ & $36 \cdot 3$ & Sanfilippo \\
\hline PS & $\mathbf{M}$ & 8 & 0 & $++t$ & 0 & + & 0.85 & 6.9 & 103 & 50.5 & $49 \cdot 5$ & Sanfilippo \\
\hline SN & $\mathbf{M}$ & 5 & 0 & +++ & 0 & + & 0.68 & $6 \cdot 7$ & 90 & $49 \cdot 2$ & 50.8 & Sanfilippo \\
\hline TB & $\mathbf{F}$ & 4 & 0 & ++ & 0 & + & 0.58 & $5 \cdot 1$ & 82 & 43.0 & $57 \cdot 0$ & Sanfilippo \\
\hline WF & $\mathbf{F}$ & 6 & 0 & $+t$ & 0 & 0 & 0.64 & 20.0 & 73 & $44 \cdot 4$ & 55.6 & Sanfilippo \\
\hline BC & $\mathbf{M}$ & 9 & 0 & + & 0 & ++ & 0.53 & 2.0 & 15 & $25 \cdot 1$ & 74.9 & Morquio \\
\hline MC & $\mathbf{M}$ & $15 \frac{1}{2}$ & ++ & 0 & + & + & 0.90 & 3.9 & 30 & $2 \cdot 7$ & $97 \cdot 3$ & Scheie \\
\hline $\mathrm{TC}$ & $\mathbf{M}$ & $15 \frac{1}{2}$ & ++ & 0 & + & + & 0.57 & 2.6 & 31 & 5.0 & 95.0 & Scheie \\
\hline $\mathbf{P}$ & $\mathbf{M}$ & 13 & $0^{1}$ & + & ++ & + & 0.68 & 3.6 & 50 & 9.6 & 90.4 & ?Scheie \\
\hline
\end{tabular}

White deposits on fundus oculi.

Clinical features were graded according to the scheme: - not assessed; 0 not present; + slight; ++ moderate; +++ severe. For assessment of cardioavascular affliction, cardiomegaly, cardiac murmur, and ECG evidence of cardiac ischaemia were considered. For assessment of skeletal affliction, kyphosis, rib and vertebral deformity, and dwarfing (height below the 94th percentile) were taken into consideration. The proportions of heparan and chondroitin sulphates, expressed as a percentage of the total sulphated urinary glycosaminoglycans, were determined electrophoretically. The final designation of type is based on both clinical and biochemical data.

consideration. When the type was not established beyond doubt, the probable type is indicated.

The C.PC turbidity was above 0.5 in every case; no false negative results were observed. At these high levels of glycosaminoglycan excretion, the CPC turbidity did not correlate so well with the CPC-precipitable uronic acid level as it did in the case of normal urines.

The CPC-precipitable uronic acid excretion was increased in each case, and the uronic acid/ creatinine ratio, which ranged from 30 in the two mildly affected cases of Scheie's syndrome, to over 300 in the most severely affected cases of Hurler's syndrome, separated cases of the Hurler, Hunter, Sanfilippo, and Scheie syndromes from controls.

Electrophoresis of the urine concentrates yielded the three major alcian-blue-positive fractions observed in normal urines (Manley et al, 1968) but in other respects the patterns differed considerably from normal (Fig. 1). One difference was quantitative. A volume equivalent to only $0 \cdot 1$ to $0.8 \mathrm{ml}$ of urine was necessary for optimal staining intensity in this study. Another difference was the proportion of glycoprotein relative to the sulphated glycosaminoglycans; one or other of the glycosaminoglycan fractions was considerably increased, so that the relative proportion of glycoprotein was greatly reduced. A third difference was in the relative proportions of the two major glycosaminoglycan fractions, corresponding in mobility to heparan and chondroitin sulphates. Two major groups were apparent within the series, one showing an increase in the fraction corresponding with chondroitin sulphate, and the other showing an increase in the fraction corresponding with heparan sulphate. Cases showing the greatest increase in chondroitin sulphate showed clinical features typical of the Hurler syndrome, with gross somatic affliction and corneal opacities. These cases also showed the highest uronic acid/creatinine ratios, in the range 130 to 330. Cases showing the greatest increase in heparan sulphate showed clinical features typical of the Sanfilippo syndrome (Sanfilippo, Podosin, Langer, and Good, 1963), with minor somatic 
affliction but severe mental retardation. These cases tended to have lower uronic acid/creatinine ratios, in the range 40 to 135 .

These two major groups were easily recognizable, but a number of cases showed patterns that did not fall exactly into either group. A third group in which there was a major increase in the chondroitin sulphate fraction, though less marked than in the true Hurler cases, showed in addition a minor increase in the heparan sulphate fraction. These cases showed similar clinical features to the Hurler syndrome, though in every case less severe, and corneal opacities did not occur. All cases were male, and they were thought to correspond clinically to the Hunter syndrome. The uronic acid/creatinine ratio was generally rather lower than in cases of the Hurler syndrome, in the range 65 to 180 .

A fourth type, showing a moderate increase in the chondroitin sulphate fraction, and if anything a decrease in the heparan sulphate fraction, showed clinical features corresponding to the Scheie syndrome, the major affliction being the development of corneal opacities. These cases showed only a moderate increase in the uronic acid/creatinine ratio, within the range 30 to 50 . The four types of electrophoretic pattern are illustrated in Figure 1.

A fifth electrophoretic pattern, characteristic of the Morquio syndrome, was expected, but results with cases labelled 'the Morquio syndrome' on clinical grounds were disappointing. Only one of four cases examined showed an increased glycosaminoglycan excretion, and no characteristic electrophoretic pattern was found.

Electrophoresis of hyaluronidase-treated samples showed that in cases exhibiting a major increase in the chondroitin sulphate fraction, the fraction was unaffected by hyaluronidase. In this respect the fraction differed considerably from that found in normal urine. In cases showing a major increase in the heparan sulphate fraction, this fraction was unaffected by hyaluronidase, as is the heparan sulphate fraction of normal urine. The chondroitin sulphate fraction in these cases was reduced by about $80 \%$ after hyaluronidase digestion.

Column chromatography of urine concentrates, and of glycosaminoglycans isolated by CPC precipitation, showed uronic acid elution patterns that corresponded only roughly with the electrophoretic patterns. In cases of the Hurler syndrome, the major uronic acid-containing fraction left the column in 1.5 to $1.7 \mathrm{M} \mathrm{NaCl}$ (Fig. 2e), as expected for chondroitin sulphate; and in cases of the Sanfilippo syndrome, the major fraction left the column in 0.6 to $1.3 \mathrm{M} \mathrm{NaCl}$ (Fig. 2f) as expected for heparan sulphate of variable sulphation. The peaks were more diffuse than on electrophoresis, and

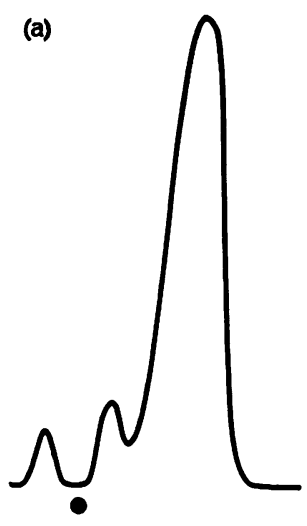

(b)

(c)
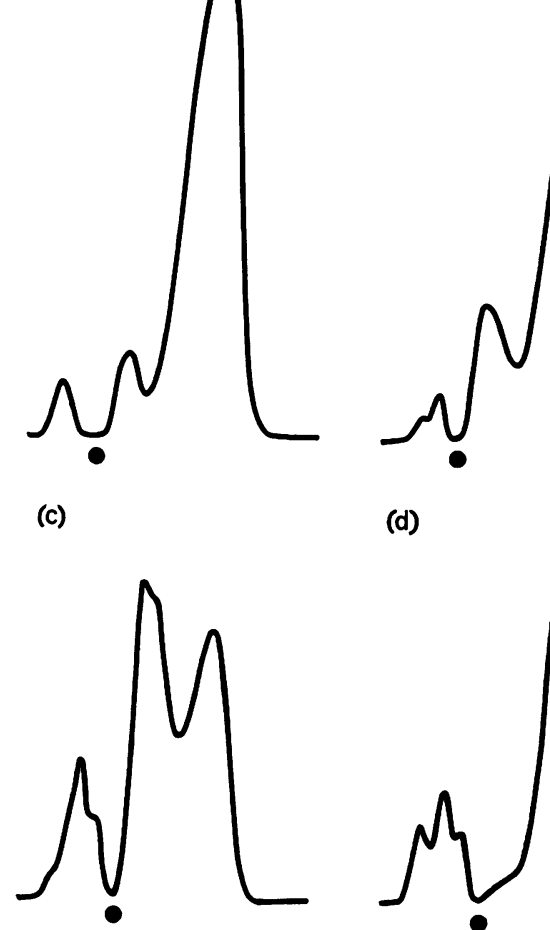

(d)

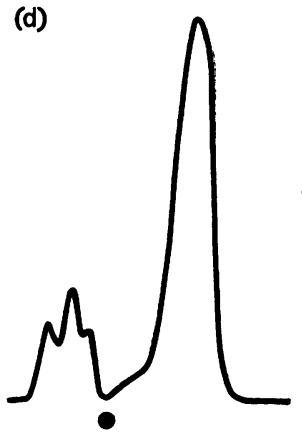

FIG. 1. Electrophoretic pattern of urinary glucosamino $\triangle$ glycans from (a) the Hurler syndrome, case $A F i$ concentrate equivalent to $0.2 \mathrm{ml}$ urine applied to strip (b) the Hunter syndrome, case PN; equivalent of $0.5 \mathrm{mb}$ urine applied to strip; (c) the Sanfilippo syndrome case $S N$; equivalent of $0.8 \mathrm{ml}$ urine applied to strip; and (d) the Scheie syndrome, case MC; equivalent of $1.0 \mathrm{mB}$ urine applied to strip.

Electrophoresis on cellulose acetate membrane a $20 \mathrm{v} / \mathrm{cm}$ for $80 \mathrm{~min}$ at $\mathrm{pH} 9.2$ and $20^{\circ} \mathrm{C}$. Strips stained with alcian blue and scanned in the Joyce Chromoscan. Electro 3 phoretic migration from left to right. The spot beneath th baseline marks the position of a standard sample of hyaluronic acid (human umbilical cord).

in the Hurler syndrome, a proportion of the uronio acid-containing material left the column before a sodium chloride molarity of 1.5 was reached, suggestew ing the presence of increased amounts of heparap sulphate in addition to chondroitin sulphate. I⿳亠े cases of the Sanfilippo syndrome, the heparaf sulphate fraction showed two ill-defined peaksef suggesting that at least two species of heparano sulphate were present.

The molar ratios of hexosamine to uronic acid if the urine concentrates were close to unity in th $\Phi^{+}$ majority of cases. In cases of the Hurler syndrome with a high uronic acid/creatinine ratio, moles of 
(a)

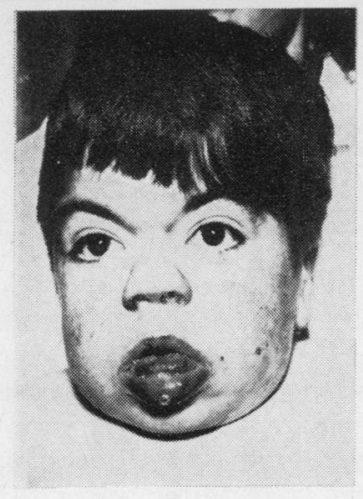

(c)

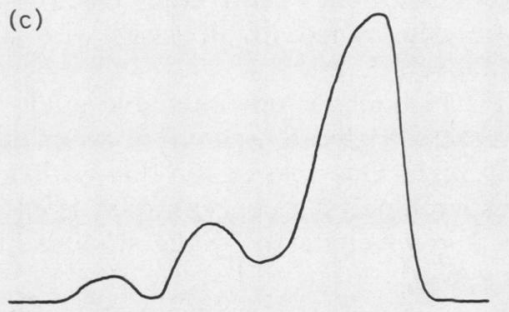

(e)

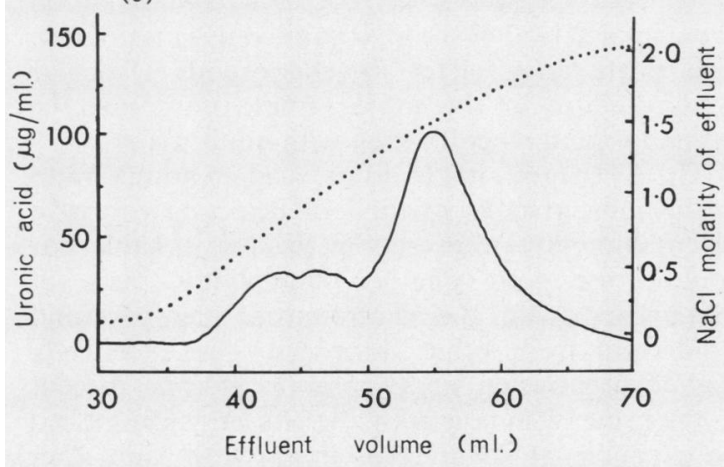

(g)
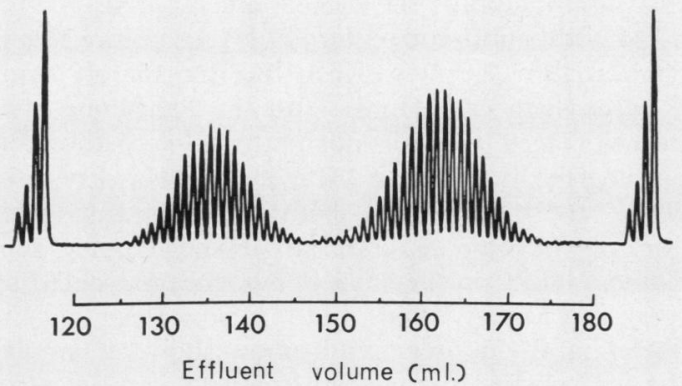

(b)

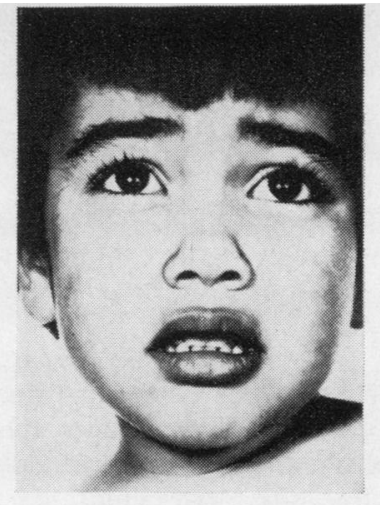

(d)

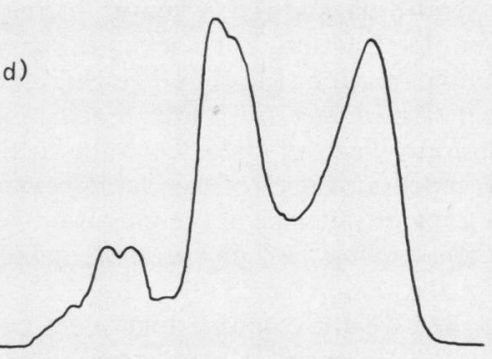

$(f)$

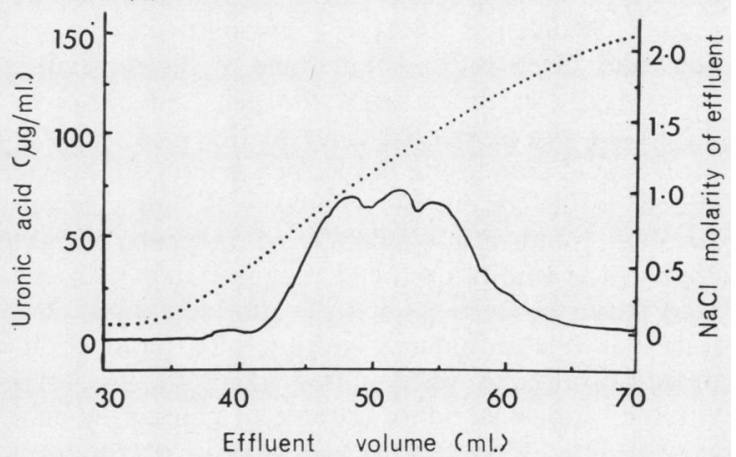

(h)
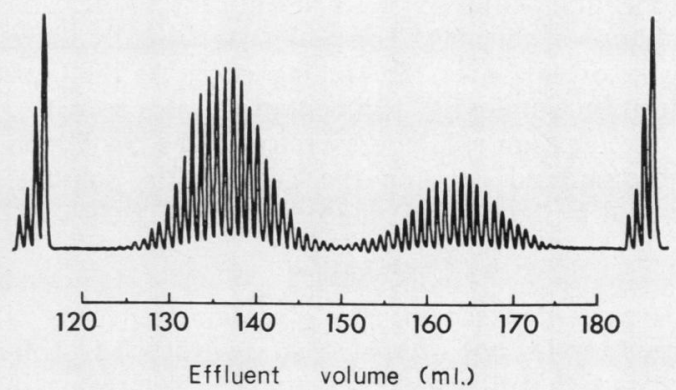

FIG. 2. Typical facies of the Hurler syndrome (a) and of the Sanfilippo syndrome (b). Electrophoretic pattern of urinary glycosaminoglycans in the Hurler syndrome (c) and in the Sanfilippo syndrome (d). Horizontal scale expanded $\times 3$ and migration from left to right. (e) Dowex 1-Cl, salt-gradient column chromatogram of urinary glycosaminoglycans in the Hurler syndrome and (f) in the Sanfilippo syndrome. Continuous flow AutoAnalyzer record of uronic acid concentration in the column effluent is represented by an unbroken line, and the $\mathrm{NaCl}$ molarity of the column effluent is represented by a dotted line. (g) Dowex 50- $\mathrm{H}^{+}$column chromatogram of aminosugars from a case of the Hurler syndrome and (h) from a case of the Sanfilippo syndrome. AutoAnalyzer record showing calibration peaks of 5, 10, 25, and $50 \mu \mathrm{g}$ hexosamine/ml at beginning and end of chromatogram. The first column peak between 125 and $145 \mathrm{ml}$ effluent is glucosamine, and the second peak between 150 and $175 \mathrm{ml}$ effluent is galactosamine. 
uronic acid outnumbered moles of hexosamine by approximately two to one. In the case of Morquio's syndrome, more hexosamine than uronic acid was present (ratio $1 \cdot 2: 1$ ).

Column chromatographic separation of the aminosugars derived from the urine concentrates by hydrolysis showed two major fractions in each case, corresponding to glucosamine hydrochloride and galactosamine hydrochloride. Cases of the Hurler syndrome showed a major increase in the galactosamine fraction, but also some increase in the glucosamine fraction (Fig. $2 \mathrm{~g}$ ). The glucosamine :galactosamine ratio was $1: 1.8$ after correcting for the lower colour yield of galactosamine in the ElsonMorgan reaction. Cases of the Sanfilippo syndrome showed a major increase in the glucosamine fraction (Fig. 2h), giving a glucosamine:galactosamine ratio of $1: 0 \cdot 6$.

Molecular weight examinations were carried out on the CPC-precipitated glycosaminoglycans from cases of the Hurler and Sanfilippo syndromes, but because of the difficulties involved in the physical examination of these highly charged polyanions, only approximate, comparative measurements were made. 'Molecular sieving' chromatography on Sephadex G 50 showed that none of the molecules were totally excluded from the gel, and although the major peak emerged close to the void volume, uronic acid-containing molecules continued to be eluted until the total volume was approached. Arterial chondroitin-6-sulphate of molecular weight 48,000 was totally excluded, being eluted with the void volume; tetrasaccharides derived from the testicular hyaluronidase-digestion of arterial chondroitin-6-sulphate were eluted close to the total volume, and a standard sample of glucuronic acid (British Drug Houses Ltd) was eluted with the total volume.

Ultracentrifugal sedimentation of the urinary glycosaminoglycans showed broad and slowlysedimenting Schlieren peaks in both the Hurler and Sanfilippo syndromes. The peaks were slightly skew, due to extension of the trailing edge. At the concentration employed, sedimentation rates were 1.0 for the heparan sulphate excreted in the Sanfilippo syndrome and 1.1 for the chondroitin sulphate excreted in the Hurler syndrome.

\section{DISCUSSION}

It is clear that the urinary glycosaminoglycans in gargoylism do not present a straightforward problem and sometimes exhibit atypical behaviour in analytical procedures. However, the excretion of glycosaminoglycans in most cases of gargoylism is so different from normal that the problem of laboratory diagnosis is straightforward.

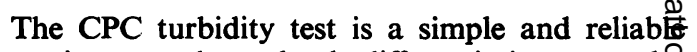
screening procedure, clearly differentiating gargoyles from the great majority of non-gargoyles, and fals negative results have not been encountered. The previous paper (Manley et al, 1968) emphasized the danger of the normally high glycosaminoglyca excretion in infancy, and the presence of excessi amounts of glycoprotein at all ages, producing an increase in the CPC turbidity, but these factoovs cannot lead to a false diagnosis of gargoylism if the uronic acid/creatinine ratio and electrophoretie pattern are determined in all cases with a CP $\vec{G}$ turbidity above $0 \cdot 5$.

The CPC turbidity is an unreliable guide to the total glycosaminoglycan excretion when this excessively high. One reason for this is that if the urine glycosaminoglycan concentration is excessives not all of it is precipitated by the amount of CPE normally added.

A serious source of error is the presence of bacter in the urine sample. Many bacteria can elabora enzymes that degrade glycosaminoglycans, and unless the concentration of merthiolate in the urine is at least $1: 10,000(\mathrm{w} / \mathrm{v})$ bacterial contaminatiof can completely alter the glycosaminoglycans presene. The degradative effect of endogenous testiculf hyaluronidase in the urine sample must also borne in mind when dealing with adult males.

The CPC-precipitable uronic acid/creatinine rati is the most reliable method of detecting excessife glycosaminoglycan excretion that is suitable for routine use, and clearly differentiates cases of gargoylism (with the exception of the Morquio syndrome) from other disorders. The excessivety high concentration of glycosaminoglycans present in the urine of some cases of the Hurler syndrome carth be a source of slight error in this test, and after sedimenting the CPC-glycosaminoglycan complex in the centrifuge, it is advisable to add more CP to the clear supernatant to ensure that all the glycosaminoglycans have been precipitated.

The electrophoretic pattern of glycosaminoglycats differentiates clearly between the two major forms of gargoylism: the Hurler and the Sanfilippo syfs dromes. These two distinct patterns were thought in an earlier publication (Manley and Hawkswort 1966), to differentiate between the autosomfal Hurler syndrome and the sex-linked Hunter syodrome, mainly on the basis of evidence presented Terry and Linker (1964), but it is now clear that the Hurler and Hunter syndromes show a similar urinary glycosaminoglycan pattern on electrophoresis. This observation does not detract from the work of Terry and Linker, for it is clear that the two techniques do not give identical results.

The differentiation between the Hurler and 
Hunter syndromes is best made at the clinical level, where evidence of X-linkage in the pedigree and absence of corneal opacities favours the Hunter syndrome. In the laboratory, the presence of an excessive excretion of testicular hyaluronidaseresistant chondroitin sulphate with a minor increase in heparan sulphate and a moderately elevated uronic acid/creatinine ratio in the range 65 to 180 is confirmatory. However, the tissue culture work of Danes and Bearn (1966a) offers a clear differentiation between the Hurler and Hunter syndromes at the laboratory level and exciting possibilities to those interested in the basic biochemical lesion.

The electrophoretic pattern in the Sanfilippo syndrome is unmistakable, a striking increase in the heparan sulphate fraction being accompanied by little or no increase in the chondroitin sulphate fraction. There is one serious source of error, again related to bacterial contamination, that must be borne in mind. Bacterial action in the urine of a case of the Hurler syndrome can reduce the electrophoretic mobility of the chondroitin sulphate present to that of heparan sulphate. This effect could result in a case of the Hurler syndrome being misdiagnosed as a case of the Sanfilippo syndrome, and the importance of adding sufficient preservative to the urine cannot be overemphasized.

The Scheie syndrome presents a clear electrophoretic pattern, with a sharp increase in the testicular hyaluronidase-resistant chondroitin sulphate fraction, and no increase, or even a decrease, in the heparan sulphate fraction. There is only a modest increase in the uronic acid/creatinine ratio. The disappointing results obtained with these techniques from cases diagnosed clinically as the Morquio syndrome are puzzling. The clinical group 'Morquio's syndrome' may be heterogeneous, including some conditions that do not have a disorder of glycosaminoglycans as the basic defect. The heterogeneity of this clinical group has also been suggested by skin fibroblast cultures (Danes and Bearn, 1967; Magrini, Fraccaro, Tiepolo, Scappaticci, Lenzi, and Perona, 1967). Techniques based on uronic acid assay will not detect an increased keratan sulphate excretion. Reliance on the total hexose or hexosamine/uronic acid ratio of urinary concentrates, or CPC precipitates, for the diagnosis of keratansulphaturia may be misleading, for increased glycoprotein excretion will also increase this ratio. The presence of excessive amounts of keratan sulphate in the urine of patients suffering from the 'Morquio-Ullrich syndrome' seems established (Zellweger, Ponseti, Pedrini, Stamler, and Von Noorden, 1961; Robins, Stevens, and Linker, 1963; Maroteaux and Lamy, 1965) and accepted as part of the Morquio syndrome by McKusick (1966), but it seems that further studies are necessary before a simple method for the diagnosis of the Morquio syndrome can be introduced to hospital laboratories.

The discrepancy between column fractionation and electrophoretic separation of urinary glycosaminoglycans in the Hurler syndrome is interesting. Although electrophoresis shows that more than $90 \%$ of the urinary glycosaminoglycan has an electrophoretic migration identical with that of chondroitin sulphate, a proportion of the uronic acid-containing material is eluted from a column of Dowex 1-C1 at a sodium chloride concentration of between 0.7 and $1.3 \mathrm{M}$, suggesting the presence of increased amounts of heparan sulphate. The measurement of glucosamine and galactosamine in acid hydrolysates of urine concentrates shows that the concentration of glucosamine is increased in addition to galactosamine, again suggesting that heparan sulphate is increased in addition to chondroitin sulphate.

An increased urinary excretion of heparan and chondroitin sulphates in cases of the Hurler syndrome is well supported (Meyer, Hoffman, Linker, Grumbach, and Sampson, 1959; Berggård and Bearn, 1965; Teller, 1967) but the electrophoretic technique used in this study shows that in fresh, uncontaminated urine, about $90 \%$ of the glycosaminoglycans excreted have a mobility corresponding with chondroitin sulphate. One explanation of this discrepancy is that an oversulphated heparan sulphate is excreted in cases of the Hurler syndrome, and this accompanies chondroitin sulphate on cellulose acetate electrophoresis, where net molecular charge is the overwhelming criterion for fractionation. Another possibility is that hybrid molecules are produced in the Hurler syndrome, with glucosamine being built into the chondroitin sulphate chain. A third possibility is that glycosaminoglycan fragments of low molecular weight may behave atypically on ion-exchange columns, being eluted at a lower salt concentration than expected. Cellulose acetate electrophoresis has the advantage of being relatively free from molecular weight effects.

The two heparan sulphate peaks in column chromatograms from cases of the Sanfilippo syndrome supports the finding of two electrophoretic fractions of heparan sulphate (Manley and Hawksworth, 1966). Knecht and Dorfman (1965) found two major fractions of heparan sulphate in Hurler tissues, differing in the degree of $\mathrm{N}$ sulphation. The data reported here are consistent with two species of heparan sulphate in urine from cases of the Sanfilippo syndrome.

Testicular hyaluronidase digestion shows that the chondroitin sulphate excreted in urine from cases of the Hurler, Hunter, and Scheie syndromes is of the 


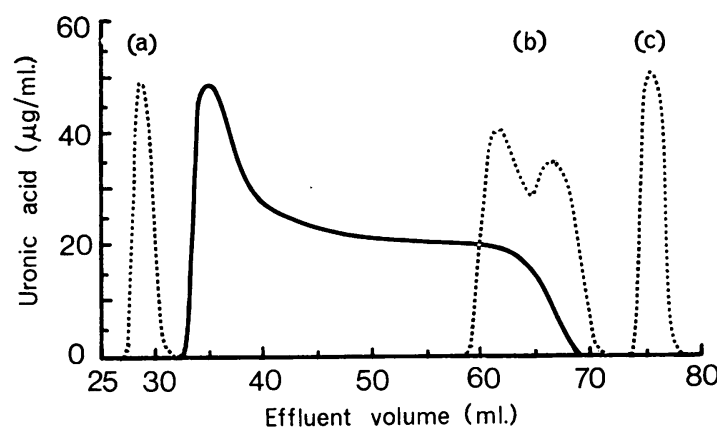

FIG. 3. Sephadex G50 gel-filtration column chromatogram of urinary glycosaminoglycans from a case of the Hurler syndrome (- $)$.

The peaks represented by dotted lines show the elution positions of (a) arterial chondroitin-6-sulphate, molecular weight 48,000; (b) tetrasaccharides produced by the action of testicular hyaluronidase on chondroitin-6-sulphate, and (c) glucuronic acid.

dermatan sulphate type (B), whereas the chondroitin sulphate in that of the Sanfilippo syndrome is chondroitin-4-sulphate or chondroitin-6-sulphate and similar to the chondroitin sulphate in normal urine.

Gel filtration of the glycosaminoglycans excreted in urine in the Hurler syndrome gives an illustration of its molecular weight polydispersity (Fig. 3); none of the chains reach a molecular weight of 50,000 , and many approach tetrasaccharide dimensions, with a spectrum of molecular weights between. The broad and slightly skew Schlieren peak observed in the ultracentrifuge also supports this observation.

The relationship between chemical excretion patterns and clinical features is interesting. Cardiovascular disease and corneal opacities develop in cases showing a preponderance of dermatan sulphate in the urine, whereas mental retardation is linked with high heparan sulphate excretion. If the Scheie syndrome is regarded as a mild forme fruste of the Hurler syndrome (Scheie, Hambrick, and Barness, 1962) showing corneal opacities as the major clinical feature, our institutions for the mentally subnormal may contain cases of unrecognized formes frustes of the Sanfilippo syndrome, with mental retardation as the major clinical feature and an increased proportion of heparan sulphate in the urine.

A correlation was observed between the uronic acid/creatinine ratio and the clinical severity of the disease. Most severely affected clinically were cases of the Hurler syndrome with uronic acid/creatinine ratios in excess of 200. These cases have a considerably reduced life expectancy, two such patients in this series having already died at the age of 6 an 11 years respectively. Cases of the Hunter syndrome. with lower uronic acid/creatinine ratios were les\$ severely affected generally. Cases of the Sanfilipp syndrome with high uronic acid/creatinine ratios showed relatively severe somatic affliction, thougf mental retardation was predominant, and such cases (when male) were often diagnosed clinically as the Hunter syndrome. Clinically diagnosed cases of the Hunter syndrome were found, on examination of the urinary glycosaminoglycans, to be divided between the "chondroitin sulphate excreting type with lower uronic acid/creatinine ratios than cases of the true Hurler syndrome, and the "heparan sulphate excreting type' with higher uronic acid creatinine ratios than cases diagnosed as of tho Sanfilippo syndrome.

Without the genetic evidence, the biochemical evidence would suggest that the Hunter syndrome did not exist as a separate entity, being an artefact of the overlapping region between mild cases of th Hurler syndrome and severe cases of the Sanfilippo syndrome.

The observation that vitamin $\mathrm{C}$ increases the्ठ synthesis of glycosaminoglycans by skin fibroblast f (Schafer, Sullivan, Svejcar, Kofoed, and Robertsone 1966) whereas retinol reduces it (Danes and Bearm? 1966b) offers a possible approach to therapy, thouge the basic defect is unlikely to be modified in this way

The most important problem-the nature of the basic defect-remains unsolved. In simplest terms the defect must be either an increased synthesis, of a decreased degradation, of glycosaminoglycans All the disorders in this group show a recessive pattern of inheritance, and recessive disorders are usually due to enzyme deficiencies (McKusick, 1966)

There are similarities between the group of disorders considered here, and the lipoidoses. There is evidence for a deficiency of $\beta$-glucosidase activit文 in Gaucher's disease (Brady, Kanfer, and Shapiroo 1965) and of sulphatase activity in metachromatic leucodystrophy (Austin, McAfee, Armstrong. O'Rourke, Shearer, and Bachhawat, 1964). Clause et al (1967) have suggested a deficiency of $\beta$-galactosaminidase activity in gargoylism, but ats present there is no experimental support for th theory. The glycosaminoglycans excreted in the urine from cases of gargoylism are all resistant to testicular hyaluronidase. Why are there no form of gargoylism involving excessive excretion of chondroitin-6-sulphate, chondroitin-4-sulphate, ox hyaluronic acid? This observation favours some difficulty in the degradative pathways of glycof saminoglycans in gargoylism ${ }^{1}$ or an abnorma

${ }^{1}$ The recent experiences of Fratantoni, Hall, and Neufeld (1968) strongly support this. 
synthesis of glycosaminoglycans that are difficult to degrade.

The alternative hypothesis concerns uncontrolled synthesis of glycosaminoglycans, and the work of Matalon and Dorfman (1966) favours this possibility. Such rogue syntheses are uncommon in genetic disorders, being more characteristic of neoplastic processes such as myelomatosis. However, some features of gargoylism favour this possibility. Dorfman (1964) suggested that the defect in Hurler's syndrome concerns the linkage of glycosaminoglycans to protein. This might result in a breakdown of feedback inhibition from the proteinpolysaccharide end product. An enzyme defect could also be incorporated into this hypothesis. If the defect were remote from the active site of the enzyme, instead involving a region sensitive to feedback inhibition, the result would be uncontrolled enzyme activity. An inherited defect of an allosteric inhibitor site in an enzyme concerned with glycosaminoglycan synthesis, or the failure of a repressor gene, would be compatible with the biochemical observations and acceptable to the geneticists.

The discovery that the biochemical phenotype persists in fibroblasts cultured from the skin of patients suffering from the Hurler syndrome (Danes and Bearn, 1966a) offers the opportunity of testing each hypothesis in controlled laboratory conditions, and it should not be long before the nature of the basic defect is revealed.

We are grateful to Mr J. R. P. O'Brien for encouragement and facilities, and to the British Heart Foundation for financial support. This study would not have been possible without the helpful collaboration and interest of many colleagues who sent us urine from patients in their care, and provided valuable clinical data. Thus we thank Professor O. Wolff, Drs M. D. Baber, F. S. W. Brimblecombe, Barbara Clayton, N. Gordon, F. Harris, B. Kirman, G. M. Lewis, S. O'Daly, A. Piesowicz, J. Spencer-Peet, J. Stern, L. Szabo, and Mr J. C. Scott. Professor O. Wolff and Dr M. D. Boser allowed us to reproduce Figure $2 a$ and $b$. We are also grateful to $\mathrm{Dr} P$. Lloyd and Miss J. Cusden for the ultracentrifuge studies.

\section{REFERENCES}

Austin, J., McAfee, D., Armstrong, D., O'Rourke, M., Shearer, L., and Bachhawat, B. (1964). Biochem. J., 93, 15c.

Berggård, I., and Bearn, A. G. (1965). Amer.J. Med., 39, 221.

Berry, H. K., and Spinanger, J. (1960). J. Lab. clin. Med., 55, 136.

Bitter, T., and Muir, H. M. (1962). Analyt. Biochem., 4, 330.

Boas, N. F. (1953). J. biol. Chem., 204, 553.

Brady, R. O., Kanfer, J. N., and Shapiro, D. (1965). Biochem. biophys. Res. Commun., 18, 221.

Clausen, J., Dyggve, H. V., Melchior. J. C., and Christensen Lou, H. O. (1967). Arch. Dis. childh., 42, 62.

Danes, B. S., and Bearn, A. G. (1966a). J. exp. Med., 123, 1. (1966b). Ibid., 124, 1181. (1967). Lancet, 1, 241.

De Lange, C., Gerlings, P. G., de Kleyn, A., and Lettinga, T. W. (1944). Acta paediat. (Uppsala), 31, 398.

Denny, W., and Dutton, G. (1962). Brit. med.J., 1, 1555.

Dorfman, A. (1964). Biophys. J., 4 (suppl.), 155.

-, and Lorinez, A. E. (1957). Proc. nat. Acad. Sci. (Wash.), 43, 443.

Fratantoni, J. C., Hall, C. W., and Neufeld E. F. (1968). Proc. nat. Acad. Sci., 60, 699.

Gardell, S. (1953). Acta chem. scand., 7, 207.

Hunter, C. (1917). Proc. roy. Soc. Med., 10, Sect. Stud. Dis. Child., 104.

Jeanloz, R. W. (1960). Arthr. and Rheum., 3, 233.

Knecht, J., and Dorfman, A. (1965). Biochem. Biophys. Res. Commun, 21, 509.

McKusick, V. A. (1966). Heritable Disorders of Connective Tissue, 3rd ed., ch. 9, p. 325. Mosby, St. Louis.

Magrini, U., Fraccaro, M., Tiepolo, L., Scappaticci, S., Lenzi, L., and Perona, G. P. (1967). Ann. hum. Genet., 31, 231.

Manley, G., and Hawksworth, J. (1966). Arch. Dis. Childh., 41, 91. - Severn, M., and Hawksworth, J. (1968). J. clin. Path., 21, 339.

Maroteaux, P., and Lamy, M. (1965). J. Pediat., 67, 312.

Matalon, R., and Dorfman, A. (1966). Proc. nat. Acad. Sci. (Wash.), $56,1310$.

Meyer, K., Hoffman, P., Linker, A., Grumbach, M. M., and Sampson, P. (1959). Proc. Soc. exp. Biol. (N.Y.), 102, 587.

Mullinger, R. N., Lloyd, P., and Manley, G. (1969). Biochem. J., in the press.

Robins, M. M., Stevens, H. F., and Linker, A. (1963). J. Pediat., 62, 881.

Sanfilippo, S. J., Podosin, R., Langer, L., and Good, R. A. (1963). Ibid., 63, 837.

Schafer, I. A., Sullivan, J. C., Svejcar, J., Kofoed, J., and Robertson, W. van B. (1966). Science, 153, 1008.

Scheie, H. G., Hambrick, G. W., Jr, and Barness, L. A. (1962). Amer. J. Ophthal., 53, 753.

Segni, G., Romano, C., and Tortorolo, G. (1964). Lancet, 2, 420.

Teller, W. M. (1967). Nature (Lond.), 213, 1132.

Terry, K., and Linker, A. (1964). Proc. Soc. exp. Biol. (N.Y.), 115, 394.

Washington, J. A. (1966). Hurler's syndrome (gargoylism): Lipochondrodystrophy, etc. In Brennemann's Practice of Pediatrics, vol. 4, chap. 30. Edited by V. C. Kelley. Prior, Hagerstown.

Zellweger, H., Ponseti, I. V., Pedrini, V., Stamler, F. S., and Von Noorden, G. K. (1961). J. Pediat., 59, 549. 